\title{
Correction
}

\section{Correction: Megill et al., A Tetra(Ethylene Glycol) Derivative of Benzothiazole Aniline Enhances Ras-Mediated Spinogenesis}

In the article "A Tetra(Ethylene Glycol) Derivative of Benzothiazole Aniline Enhances Ras-Mediated Spinogenesis” by Andrea Megill, Taehee Lee, Amanda Marie DiBattista, Jung Min Song, Matthew H. Spitzer, Mark Rubinshtein, Lila K. Habib, Christina C. Capule, Michael Mayer, R. Scott Turner, Alfredo Kirkwood, Jerry Yang, Daniel T. S. Pak, Hey-Kyoung Lee, and Hyang-Sook Hoe, which appeared on pages 9306-9318 of the May 29, 2013 issue, Figure 1, E and F, showed representative blots where sAPP $\alpha$ was increased with drug treatment (B vs C), but full-length APP was unchanged. Recently, it was discovered that the $\beta$-actin blots shown in these figures do not correspond directly with the sAPP $\alpha$ and full-length APP blots. This correction does not change our conclusions, figure legend, or data quantification. A corrected figure is presented below.

A

Wild-type mice

BTA-EG $4(10 \mathrm{mg} / \mathrm{kg})$
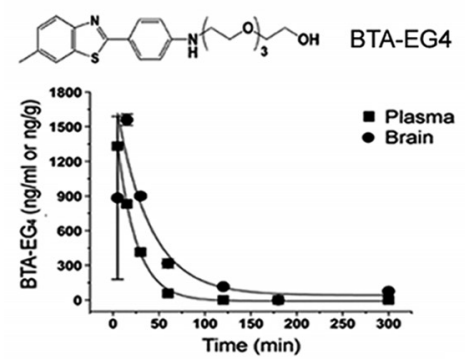

D Wild-type mice

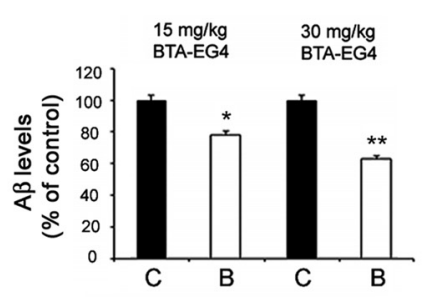

H

cos7 cells

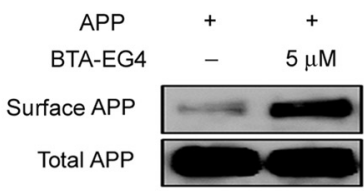

I Primary cortical neurons

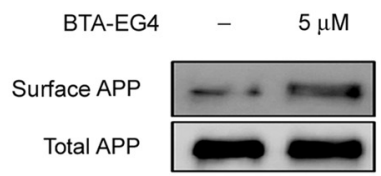

B

\begin{tabular}{lc}
\hline Pharmacokinetic parameters & Value \\
\hline$t_{1 / 2 \text { plasma }(\min )}$ & 14 \\
$t_{1 / 2}$ brain $(\min )$ & 27 \\
C max plasma $(\mathrm{ng} / \mathrm{ml})$ & 1300 \\
C max brain $(\mathrm{ng} / \mathrm{g})$ & $1600 \pm 48$ \\
AUC plasma & 26000 \\
AUC brain & 69600 \\
Brain:Plasma ratio (BB) & 2.68 \\
Log (BB) & 0.43 \\
\hline
\end{tabular}

F WT mice

C B C B

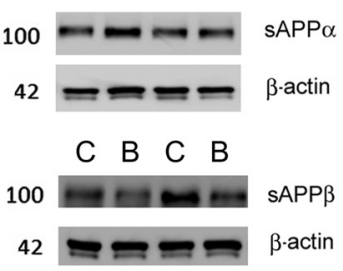

C Primary cortical neurons

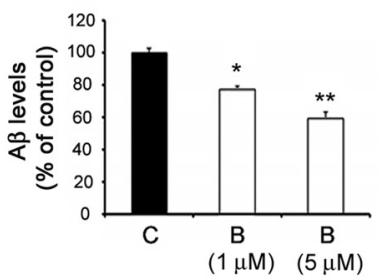

G

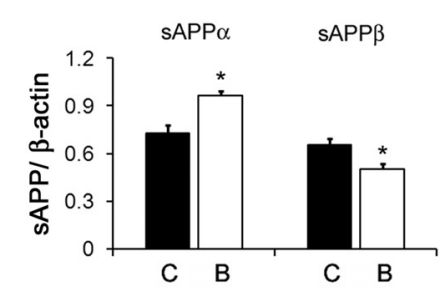

J Primary hippocampal neurons
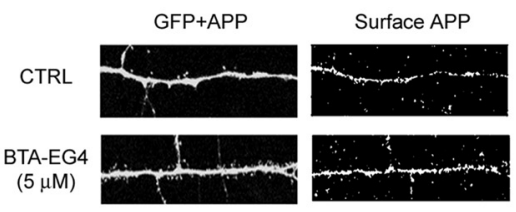

K Primary hippocampal neurons

CTRL

BTA-EG4 $(5 \mu \mathrm{M})$
GFP+APP

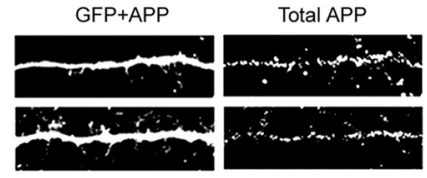

Full length APP

APP CTF

$\beta$-actin

Figure 1. 